Case Reports
in Dermatology

\title{
A Case Report of Prurigo Nodularis- Like Lesions in a Patient with Lepromatous Leprosy
}

\author{
Siwanon Nawalerspanya Siripan Sangmala Kumpol Aiempanakit \\ Division of Dermatology, Department of Internal Medicine, Faculty of Medicine, Prince of \\ Songkla University, Hat Yai, Thailand
}

\section{Keywords}

Lepromatous leprosy · Histoid leprosy · Prurigo nodularis · Histopathology · Hansen's disease

\begin{abstract}
Leprosy or Hansen's disease is a chronic granulomatous infection that primarily affects the peripheral nerves and, consequently, the skin. Clinical manifestations vary from hypopigmentation to erythematous plaques, and it can present with leonine facies. We report a case of a patient with an uncommon clinical presentation of prurigo nodularis-like lesions without loss of sensation, for which two biopsy specimens demonstrated different histological subtypes. The first was the classic histology of lepromatous leprosy, whereas the other specimen revealed an atypical histoid leprosy variant pattern. This case report describes a patient with an atypical presentation of leprosy.

(C) 2020 The Author(s)

Published by S. Karger AG, Basel
\end{abstract}

\section{Introduction}

Leprosy is a chronic infectious disease caused by the bacillus Mycobacterium leprae. Although the World Health Organization (WHO) has formally designated leprosy as a neglected tropical disease, the current global data report 208,619 new cases per year as of 2018 [1]. In Thailand, the incident rate is 0.18 cases per 100,000 persons (119 new cases) in 2019 [2]. Leprosy primarily affects the peripheral nerves and, consequently, the skin and leads to longterm morbidity despite antimicrobial treatment.

The clinical skin presentations of the disease are dependent on the host defense mechanism and the number of bacilli. Lepromatous leprosy (LL) is the most severe form manifesting 


\section{Case Reports in Dermatology}

Case Rep Dermatol 2020;12:236-240

DOI: $10.1159 / 000510737$

C 2020 The Author(s). Published by S. Karger AG, Basel www.karger.com/cde

Nawalerspanya et al.: A Case Report of Prurigo Nodularis-Like Lesions in a Patient with Lepromatous Leprosy

with the least cellular immunity, the highest humoral immunity response, and an enormous amount of organisms. It is characterized by numerous ill-defined erythematous nodules and plaques commonly occurring on the face, buttocks, and lower extremities. Histoid leprosy $(\mathrm{HL})$, a rare variant of LL, manifests as soft nodules and plaques overlain with normal skin and has a unique histopathology [3]. Herein, we report a case of an Asian man who presented with a long period of clinically identified prurigo nodularis and who had the two dermatopathological subtypes of LL based on his skin manifestations.

\section{Case Report}

A 68-year-old Asian man presented with numerous progressive itchy papules on the legs, torso, and upper extremities for 2 years. He had sought treatment at a different hospital where he was treated with antihistamines, topical corticosteroids, and a short course of systemic steroids, but without improvement.

He also had various medical conditions, notably hypertension, coronary artery disease, hypertrophic cardiomyopathy, and gouty arthritis. Not long before the reported admission, he had been admitted for an extensive pulmonary embolism causing deep vein thrombosis. His current medications were aspirin, clopidogrel, carvedilol, nifedipine, simvastatin, omeprazole, colchicine, and warfarin. He also had a 10-year history of alcohol consumption and a 40-year history of tobacco smoking. However, there was no family history of skin diseases, including leprosy.

Skin examination revealed multiple, hyperpigmented papules with some central erosion and crusts distributed on the abdomen and extremities (shown in Fig. 1a-c). The hair, nails, mucous membranes, and lymph nodes were normal. Neurological examination revealed normal pinprick sensations, no muscle weakness, and no nerve enlargement. The differential diagnoses were prurigo nodularis, lymphomatoid papulosis, perforating disorders, and papulonecrotic tuberculid.

Two skin biopsies on the right arm were performed. The first specimen obtained from a lesion with an erythematous papule revealed normal epidermis and keratin. The dermis exhibited a diffuse foamy histiocytic infiltrate with globi formations and the appearance of a Grenz zone (shown in Fig. 2a-b). Fite's staining showed a strongly positive result for numerous bacilli (shown in Fig. 2c). The second section obtained from a hyperkeratotic papule exhibited compact orthokeratosis with mild irregular acanthosis of the epidermis (shown in Fig. 2d). Diffuse fusiform and foamy histiocytic infiltrate with several globi formations was observed in the dermis. The histiocytes were arranged in a whorled pattern at the upper to the middle dermis (shown in Fig. 2e). The Grenz zone was not detected in this section. Fite's staining also showed a strongly positive result for bacilli (shown in Fig. 2f).

The patient was administered with a modified WHO-recommended multidrug therapy regimen (rifampicin, dapsone, and clofazimine) for 24 months. After 6 months of treatment, his skin lesions and itching symptoms were improved, in addition to the absence of leprosy reactions.

\section{Discussion}

The typical clinical manifestations of LL are generalized erythematous nodules and plaques. However, the patient described in this case report presented with prurigo nodularis- 


\section{Case Reports in Dermatology}

Case Rep Dermatol 2020;12:236-240

DOI: $10.1159 / 000510737$

C 2020 The Author(s). Published by S. Karger AG, Basel www.karger.com/cde

Nawalerspanya et al.: A Case Report of Prurigo Nodularis-Like Lesions in a Patient with Lepromatous Leprosy

like lesions for 2 years and was initially treated for prurigo nodularis. It was difficult to make the diagnosis because the prurigo nodularis-like lesions and the symptoms of no loss of sensation and the absence of local nerve enlargement are not characteristic features of leprosy. Therefore, the diagnosis necessitated histopathological studies. The sections from the two prurigo nodularis-like lesions exhibited a typical LL and a rare variant type of LL, HL. This case presents two different histological patterns clinically mimicking prurigo nodularis, which makes it difficult to diagnose leprosy; this finding can also contribute to the prevalence of the disease where a differential diagnosis is not performed.

Although HL is not a common form of leprosy, it is important to consider it because of the multibacillary pathogens $[3,4]$. The clinical presentation generally includes subcutaneous nodules, which are not typical in LL. The differential diagnosis of HL must include xanthoma, neurofibroma, dermatofibroma, reticulohistiocytosis, and cutaneous metastasis [3]. Although it is difficult to diagnose HL, some clinical clues can help, such as a previous diagnosis of leprosy treated with dapsone monotherapy, abnormal neuropathy, and leonine facies [5, 6]. LL usually does not affect the sensation [7]. An HL patient was reported with pruritic papules and nodules [8]. The possible pathophysiological mechanism is neuropathic itch. Skin lesions such as shingles and leprosy can affect the peripheral nerve fibers resulting in damage itch-transducing, conducting or processing neurons, causing neuropathic itch [9].

Based on the atypical presentations, the physician must be suspicious of HL. The initial investigation in suspected cases is a slit-skin smear prepared from a lesion to look for the organisms. The histopathology of HL exhibits a predominance of spindle-shaped histiocytes, forming interlacing bands, whorls, or storiform patterns and a large number of acid-fast bacilli $[3,10]$. The epidermis overlying the lesion is generally atrophied. A recent study reported that histopathological examinations could reveal classical LL in the center but with features of HL in the periphery of the lesions [11]. The authors of that study recommended performing an elliptical scalpel biopsy for making a reliable diagnosis.

To date, there is no standard regimen recommended for $\mathrm{HL}$, but the current treatment for multibacillary leprosy can be used for a patient with $\mathrm{HL}[3,12,13]$. Recent recommendations for HL comprise screening the patient's family and chemoprophylaxis, with a single dose of rifampicin, to close contacts [14].

\section{Conclusion}

HL is a rare form of LL. This case study describes a case of de novo HL clinically mimicking prurigo nodularis. Histopathological examinations demonstrated the specific patterns of HL combined with typical LL. Knowledge about the atypical manifestations might provide suggestions and recommendations to clinicians and researchers about the differential diagnoses, which would clarify this form of leprosy mimicking prurigo nodularis, especially when the patients present with chronic recalcitrant itching papules and nodules, thus allowing the diagnosis of leprosy.

\section{Acknowledgments}

We would like to thank Enago (www.enago.com) for English language editing. 


\section{Case Reports in Dermatology}

\begin{tabular}{l|l}
\hline DOI: $10.1159 / 000510737$ & (c) 2020 The Author(s). Published by S. Karger AG, Basel
\end{tabular} www.karger.com/cde

Nawalerspanya et al.: A Case Report of Prurigo Nodularis-Like Lesions in a Patient with Lepromatous Leprosy

\section{Statement of Ethics}

Written informed consent to publish this case (including images) was obtained from the patient. The research was conducted ethically in accordance with the World Medical Association Declaration of Helsinki. This case report was approved by the Research Ethics Committee, Faculty of Medicine, Prince of Songkla University (REC. 62-063-14-1).

\section{Conflict of Interest Statement}

There are no conflicts of interest.

\section{Funding Sources}

None.

\section{Author Contributions}

S.N. and S.S. drafted the manuscript and K.A. revised it critically for important intellectual content. S.S., S.N., and K.A. were involved in the conception of this case report and gave final approval of the version published.

\section{References}

1 World Health Organization [Internet]. Leprosy: new data show steady decline in new cases [cited 2019 September 9]. Available from https://www.who.int/neglected_diseases/news/Leprosy-new-data-showsteady-decline-in-new-cases/.

2 Rajpracha Samasai Foundation under the Royal patronage, Ministry of Public Health [Internet]. [Leprosy situation in Thailand, 2019. Article in Thai] [cited 2020 July 15] Available from http://thaileprosy.ddc.moph. go.th/site/index.htm.

3 Gupta SK. Histoid leprosy: review of the literature. Int J Dermatol. 2015 Nov;54(11):1283-8.

4 Karthikeyan K. Histoid leprosy. Am J Trop Med Hyg. 2015 Jun;92(6):1085-6.

5 Nair SP, Nanda Kumar G. A clinical and histopathological study of histoid leprosy. Int J Dermatol. 2013 May;52(5):580-6.

6 Triscott JA, Nappi O, Ferrara G, Wick MR. “Pseudoneoplastic” leprosy. Leprosy revisited. Am J Dermatopathol. 1995 Jun;17(3):297-302.

7 Ramos-e-Silva M, Ribeiro de Castro MC. Mycobacterial infections. In: Bolognia JL, Schaffer JV, Cerroni L, editors. Dermatology. 4th ed. China: Elsevier; 2018. pp. 1296-316.

8 Sánchez-Orta A, Albízuri Prado MF, González Pessolani T, Sendagorta Cudós E. Pruritic lesions during pregnancy: an unusual presentation of a rare variant of multibacillary leprosy. Actas Dermosifiliogr. 2016 May;107(4):352-4.

9 Steinhoff M, Oaklander AL, Szabó IL, Ständer S, Schmelz M. Neuropathic itch. Pain. 2019 May;160 Suppl 1:S11-6.

10 Canuto MJ, Yacoub CR, Trindade MA, Avancini J, Pagliari C, Sotto MN. Histoid leprosy: clinical and histopathological analysis of patients in follow-up in University Clinical Hospital of endemic country. Int J Dermatol. 2018 Jun;57(6):707-12.

11 Rodrigues Daxbacher EL, Cabrera Pereira JP, Ramos de Oliveira S, Duarte Tortelly V, Carneiro S, Jeunon T. The Importance of the Biopsy Technique in the Diagnosis of Histoid Leprosy. Am J Dermatopathol. 2020 Feb;42(2):125-8.

12 Kaur I, Dogra S, De D, Saikia UN. Histoid leprosy: a retrospective study of 40 cases from India. Br J Dermatol. 2009 Feb;160(2):305-10.

13 Chaptini C, Marshman G. Leprosy: a review on elimination, reducing the disease burden, and future research. Lepr Rev. 2015 Dec;86(4):307-15.

14 Venkatesan S, Thangaraju P. De novo histoid leprosy - Further points of focus. Rev Soc Bras Med Trop. 2019 Sep;52:e20190334. 


\section{Case Reports in Dermatology}
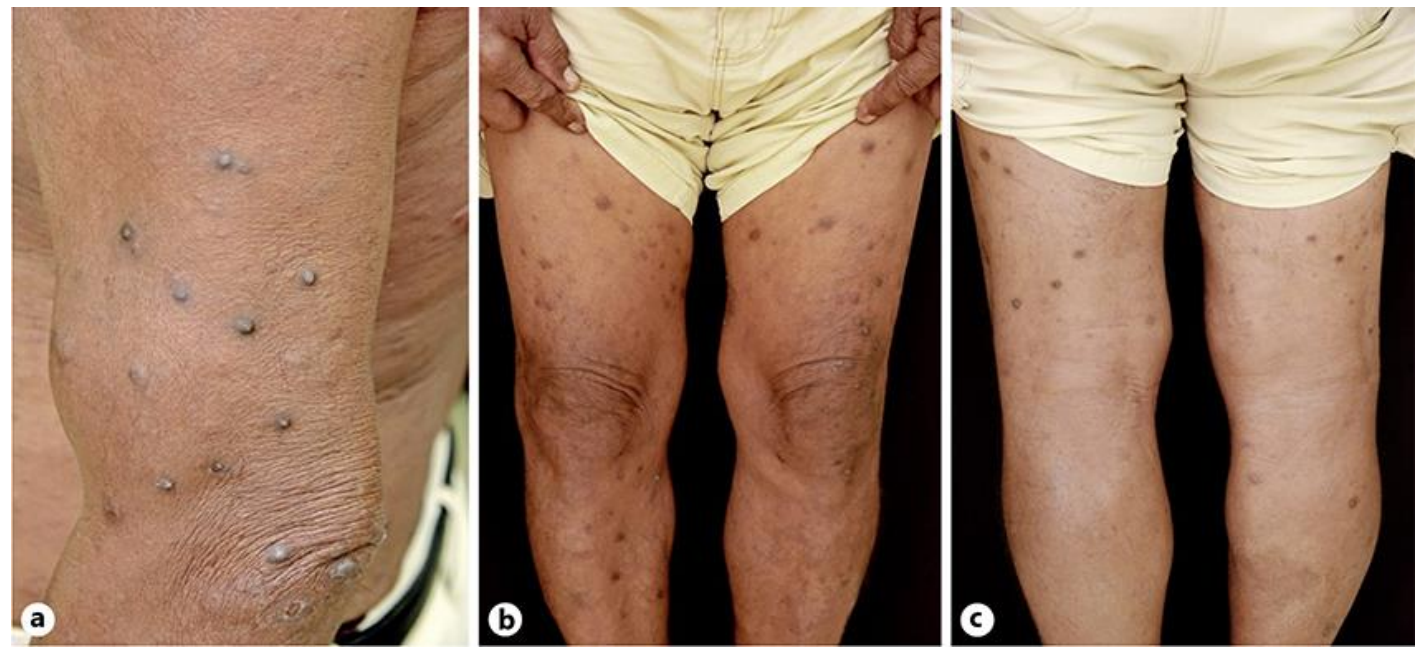

Fig. 1. a-c Photographs of the patient with prurigo nodularis-like lepromatous leprosy.
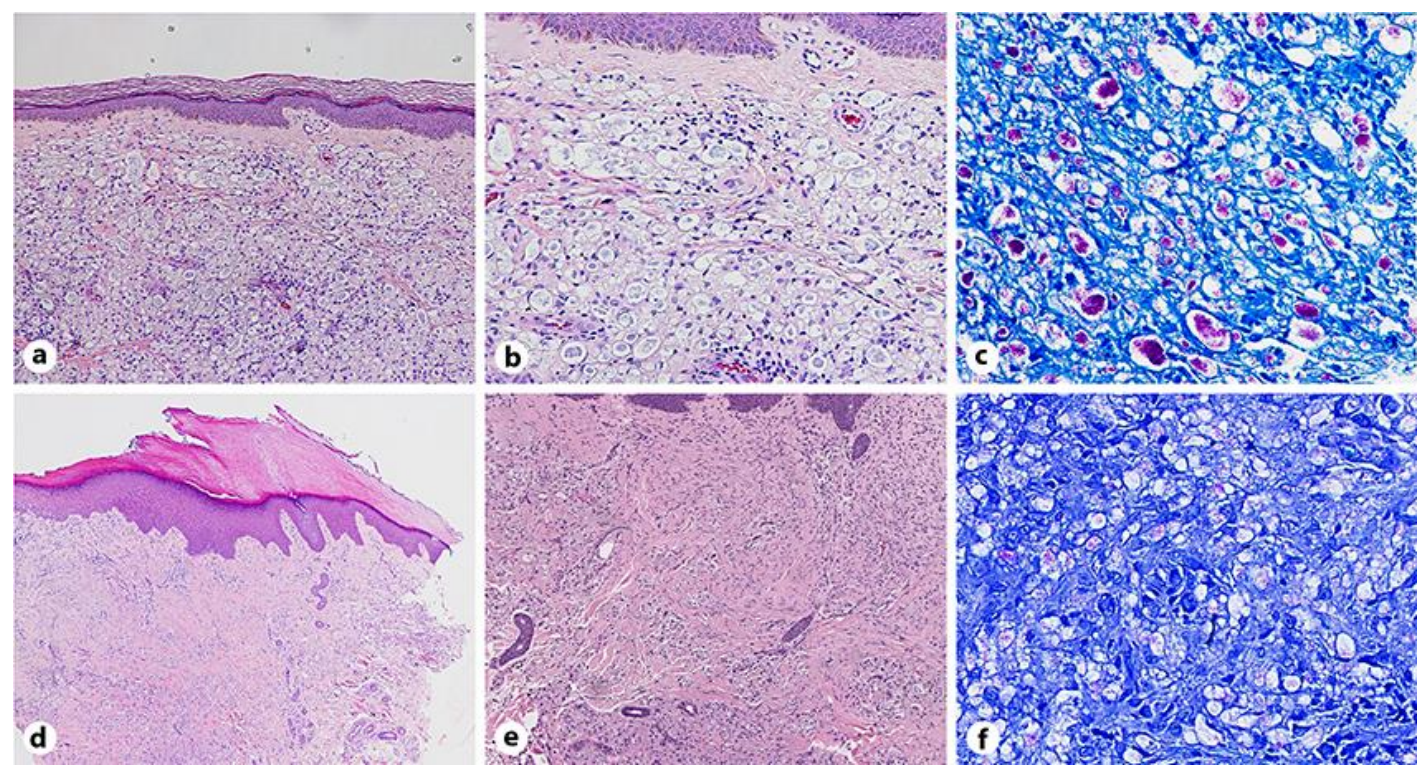

Fig. 2. a-f Skin biopsy specimens from the left upper arm. a-c From erythematous papules. a, b The dermis shows a diffuse foamy histiocytic infiltrate with globi formation and the appearance of a Grenz zone (H\&E, a $20 \times$, b $40 \times$ ). c Fite's stain was strongly positive, showing numerous bacilli (Fite's stain, $60 \times$ ). d-f From hyperkeratotic papule. $\mathbf{d}$ The keratin exhibited compact orthokeratosis with mild irregular acanthosis of the epidermis (H\&E, 4×). e Diffuse fusiform and foamy histiocytic infiltrate, several globi formations in the dermis, and the histiocytes arranged in a whorled pattern at the dermis (H\&E, 20×). f Fite's stain was strongly positive (Fite's stain, 60×). 